\title{
A double-blind randomized clinical trial on the efficacy of magnetic sacral root stimulation for the treatment of Monosymptomatic Nocturnal Enuresis
}

\author{
Eman M. Khedr ${ }^{\mathrm{a}, *}$, Khaled A. Elbeh ${ }^{\mathrm{a}}$, Ahmed Abdel Baky ${ }^{\mathrm{a}}$, Noha Abo-Elfetoh ${ }^{\mathrm{a}}$, \\ Dina H. El-Hammady ${ }^{\mathrm{b}}$ and Fatma Korashy ${ }^{\mathrm{a}}$ \\ ${ }^{a}$ Department of Neuropsychiatry, Assiut University Hospital, Assiut, Egypt \\ ${ }^{\mathrm{b}}$ Department of Rheumatology and Rehabilitation, Assiut University Hospital, Assiut, Egypt
}

\begin{abstract}
.
Purpose: Purpose of this study was to evaluate the long term efficacy of repetitive sacral root magnetic stimulation (rSMS) in patients with monosymptomatic nocturnal enuresis (MNE).

Methods: Forty four patients were randomized to receive either sham or real repetitive sacral root magnetic stimulation (rSMS; $15 \mathrm{~Hz}$ with a total of 1500 pulses/session) for 10 sessions. Evaluation was performed before starting treatment, immediately after the 5th and 10th treatment session, and 1 month later, using frequency of enuresis/week, visual analogue scale (VAS) and quality of life as outcome measures. Resting and active motor thresholds of gastrocnemius muscles were measured before and after the end of sessions.

Results: Both treatment and control groups were comparable for baseline measures of frequency of enuresis, and VAS. The mean number of wet nights/week was significantly reduced in patients who received real rSMS. This improvement was maintained 1 month after the end of treatment. Patients receiving real-rSMS also reported an improvement in VAS ratings and quality of life. A significant reduction of resting motor threshold was recorded after rSMS in the real group while no such changes were observed in the sham group.

Conclusion: These findings suggest that rSMS has potential as an adjuvant treatment for MNE and deserves further study.
\end{abstract}

Keywords: Nocturnal enuresis, quality of life, targeted electrical or magnetic sacral root stimulation, repetitive sacral root magnetic stimulation

ClinicalTrials.gov Registration <register@clinicaltrials.gov>

Clinical trial gov. Identifier: NCT 02328092

\section{Introduction}

Bedwetting is a widespread and distressing condition that can have a deep impact on a child or young person's behavior, emotional wellbeing and social life. It is

*Corresponding author: Prof. Dr. Eman M. Khedr, Department of Neurology, Faculty of Medicine, Assiut University Hospital, Assiut, Egypt. Tel.: +20 088 2089355; Fax: +20 088 2333327; E-mail: emankhedr99@yahoo.com. also very stressful for parents and caregivers (Butler \& Heron, 2008). The American Psychiatry Association's DSM-IV defines primary nocturnal enuresis (PNE) as repeated urination into bed or clothes, occurring twice per week for at least three consecutive months in a child of at least 5 years of age and not due to either a drug side effect or a medical condition (American Psychiatric Association's DSM-IV, 1994). The causes of bedwetting are not fully understood. Bedwetting can be 
considered to be a symptom that may result from a combination of different predisposing factors. There are a number of different disturbances of physiology that may be associated with bedwetting. These disturbances may be categorized as sleep arousal difficulties, polygraph and bladder dysfunction (Nevéus, 2003; Deshpande \& Caldwell, 2012).

Monosymptomatic nocturnal enuresis (MNE) describes those patients with nocturnal enuresis in the absence of any other lower urinary tract symptom, i.e. increased or decreased frequency of micturition, daytime urinary incontinence, urgency, hesitancy, straining, a weak urinary stream, intermittency, voiding postponement maneuvers, a feeling of incomplete micturition, post-micturition dribble and genital or lower urinary tract pain (Lottmann \& Alova, 2007).

Despite the growing body of neuroimaging data and the emergence of neural models of PNE (Butler \& Holland, 2000), there is a lack of targeted treatment interventions. A number of different types of electrical stimulation (invasive and non-invasive) have been applied in patients with urinary incontinence. Caldwell's (1963) first efforts used an electrode that was implanted into the periurethral musculature and controlled remotely. Percutaneous stimulators and direct sacral nerve stimulators have been described (Lordêlo et al., 2010). A removable stimulator that could be applied either vaginally or anally has also been reported (Suhel, 1976; Glen et al., 1976). Sacral electrical stimulation has been employed in the treatment of urgency-frequency syndromes, urge incontinence, interstitial cystitis and voiding dysfunction (Van Balken et al., 2004).

More recently, magnetic stimulation has been proposed as a potential method for stimulation of sacral nerves (Khedr et al., 2011). It is believed to have the same underlying effect as functional electrical stimulation since it generates an electrical field resulting similar to that produced by conventional electrical stimulators (Karim et al., 2003). However, unlike direct electrical stimulation which decreases as a function of tissue impedance, the magnetic field penetrates tissues with little impedance and falls off in magnitude as the inverse square of the distance (Lisanby et al., 2001). So, theoretically, a greater effect can be achieved on neural tissue at greater depths with less discomfort at the point of application. It is thus an attractive form of electrical therapy, being relatively painless, non-invasive and free from side effects. It is also convenient as magnetic fields pass through clothing (Quek, 2005).
Fujishiro et al. (2002) reported that magnetic stimulation of the sacral roots for the treatment of urinary frequency and urge incontinence produced a useful improvement in symptoms. Khedr et al. (2011) also found that repetitive lumbosacral root magnetic stimulation (rLMS) at $15 \mathrm{~Hz}$ may improve urinary dysfunction secondary to lumbosacral nerve injury. A comparative study investigating the urodynamic effects of functional magnetic stimulation (FMS) (pulsegen device) and functional electrical stimulation (FES) (a vaginal electrode in women and a surface electrode on the dorsal part of the penis in men) found that both treatments reduced detrusor overactivity with FMS being slightly superior to FES (Yamanishi et al., 2000). Efficacy has been shown to improve with the number of sessions whereas most study protocols having 12 to 16 sessions (Almeida et al., 2004).

Most of the previous studies examined effects of FMS in cases of neurogenic bladder. There have been few studies of its effects on primary nocturnal enuresis because neuromodulation has not been widely accepted as a first-line treatment. Promising results were obtained by maximal electrical stimulation (MES) in enuretic children (Trsinar et al., 1984; Plevnik et al., 1986), while But and Varda (2006) noted improvements following functional magnetic stimulation (FMS) in girls with PNE.

Lordêlo et al. (2010) reported reduced symptoms following treatment of non-monosymptomatic nocturnal enuresis with transcutaneous parasacral electrical nerve stimulation.

There have been a number of reports of a positive response to sacral root stimulation using either magnetic (Yamanishi et al., 1999; But \& Varda, 2006) or electrical (Trsinar \& Kraij, 1996; Lordêlo et al., 2010) stimulation in children with PNE. Given that bladder overactivity is common in PNE (Yeung et al., 1999), a combination of medical and neuromodulation can be more effective than monotherapy.

Repetitive high-frequency lumbosacral magnetic stimulation (rLMS) at $15 \mathrm{~Hz}$ was found to change cortico-anal excitability (Harris et al., 2008) in healthy subjects and may therefore have a therapeutic effect in patients with sphincter dysfunction as previously reported (Khedr et al., 2011).

Therefore we hypothesized that rSMS at $15 \mathrm{~Hz}$ combined with an anticholinergic drug might be effective in the treatment of MNE.

The aim of the study was to evaluate the long term efficacy of rSMS in patients with MNE. We applied 
10 sessions of high frequency sacral root stimulations in a double blind randomized trial of patients with MNE.

\section{Material and methods}

\subsection{Material}

This trial is reported following 2010 CONSORT guidelines.

This study was conducted at the Neuropsychiatry department, Assiut University Hospital from May 2013 to May 2014. All subjects were diagnosed as patients with MNE according to the Diagnostic and statistical manual of mental disorders, 4th revised edition (DSM-IV) (American Psychiatric Association's DSM-IV, 1994). The mean age (SD) was 13.6 (3.3) years ranging from 8-25 years as an inclusion criteria. The exclusion criteria were as follow: radiculopathy, Diabetes Mellitus, spinal cord lesion, spina bifida, local urological causes and peripheral neuropathy. Fifteen nocturnal enuresis patients were recruited in the present study; 6 cases were excluded ( 2 had day and night enuresis, two have severe urinary tract infection and last two cases had history of juvenile diabetes) and remaining 44 cases were eligible for the present study, who divided equally for assignment to real or sham treatment (22 patients for each group). Only 41 nocturnal enuresis patients completed the study (see Fig. 1 flow chart). All patients had been taking the tricyclic antidepressant drug imipramine $(25 \mathrm{mg}$ once at night /day) for at least 3 months without satisfactory results and they continued taking their usual drugs throughout the study. All patients received behavioral orientation for NE, involving urination before going to bed, and avoiding coffee, tea, soft drinks and chocolate one month before beginning sacral root stimulation.

\subsection{Clinical assessment}

Each subject underwent a clinical neurological examination, and completed a visual analogue scale (VAS) to determine how much the enuresis affected her life as well as a generic SF-36v2 Health Survey (Stewart \& Ware, 1992) to compare the disease (enuresis) burden across populations. The Survey includes 36 questions to measure functional health and well-being from the patient's point of view. It is a practical, reliable and valid measure of physical and mental health

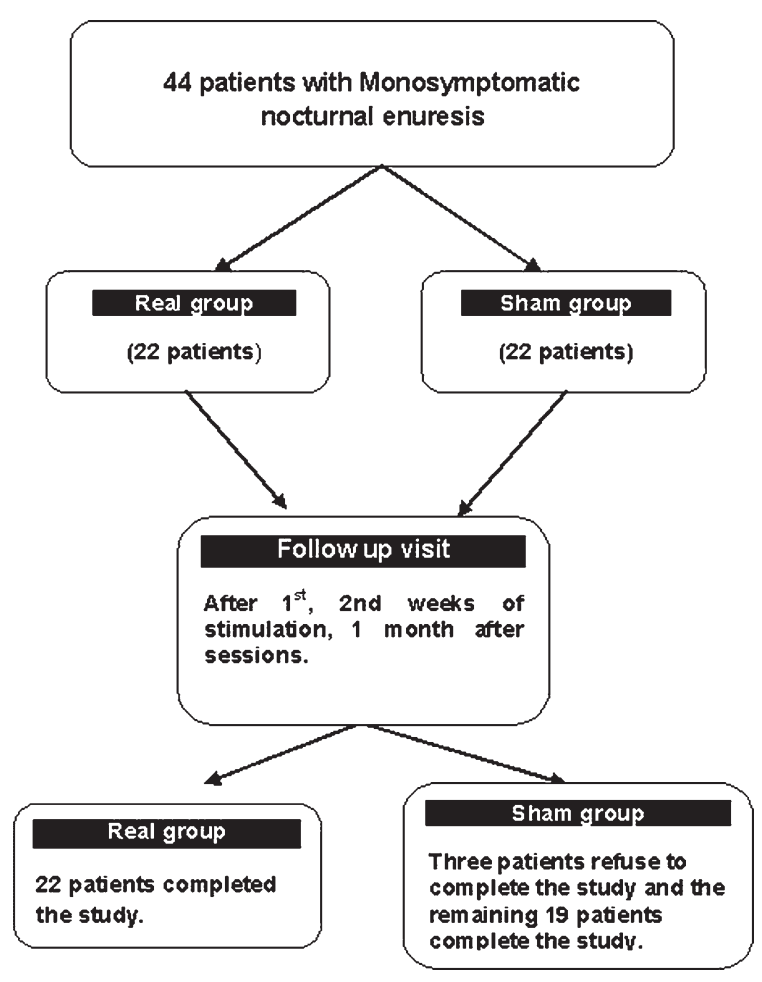

Fig. 1. Flow chart of the patients through the course of the study.

that can be completed in five to ten minutes. The SF-36v2 provides scores for each of the eight health domains and psychometrically-based physical component summary (PCS) and mental component summary (MCS) scores. The success of treatment was reported by patients on the basis of a visual analog scale $(0 \%$, no change in symptoms after rSMS to $100 \%$, no enuresis after rSMS). All female patients and control subjects were tested outside the period of menstruation.

\subsection{Neurophysiological investigations}

F waves were recorded from the gastrocnemius muscle after supramaximal electrical stimulation of the posterior tibial nerves at the popliteal fossa. 10 stimuli were given, and the average latency value was determined for each leg to confirm that lumbosacral root function was normal.

\subsection{Determination of motor thresholds}

Resting and active motor thresholds (RMT and AMT, respectively), and motor evoked potentials 
(MEP) were assessed in the gastrocnemius muscles. Participants sat in a comfortable chair. Electromyographic (EMG) recordings from the gastrocnemius were acquired with silver-silver chloride surface electrodes, using a muscle belly-tendon set-up with a $3 \mathrm{~cm}$ diameter circular ground electrode placed on the wrist.

A Nihon Kohden Machine model 9400 (TokyoJapan) was used to record the EMG parameters using a bandpass of $20-1000 \mathrm{~Hz}$ and a recording time window of $200 \mathrm{~ms}$. TMS was performed with a $90 \mathrm{~mm}$ figure of eight coil connected to Magstim super rapid magnetic stimulator (Magstim limited company-UK).

Thresholds were determined after localization of the motor hot spot for the gastrocnemius muscle in each hemisphere. Relaxation and EMG signals were monitored and recorded for $20 \mathrm{~ms}$ prior to stimulation. The RMT was defined as the minimal intensity required eliciting motor evoked potentials of $50 \mu \mathrm{V}$ peak-topeak amplitude in five out of 10 consecutive trials.

The AMT was determined in the same way while subjects made a mild contraction of about $10 \%$ of maximum contraction judged by audio-visual feedback. AMT was defined as the minimal intensity required eliciting an MEP larger than $200 \mu \mathrm{V}$ in five out of 10 consecutive trials. Both the RMT and the AMT were expressed as a percentage of the maximal stimulator output (equal to $100 \%$ ).

\subsection{Randomization}

The patients were randomly assigned to 1 of the 2 groups using serially numbered opaque closed envelopes that were used for allocation concealment. Allocation was maintained throughout the study. To ensure double blinding, the random allocation sequence was kept by an investigator different from the one who enrolled the participants or assigned them to the interventions. Moreover, a third investigator was responsible for following the patients up and for assessment. The patients didn't know which type of stimulation was received.

\subsection{Repetitive Sacral root Magnetic Stimulation (rSMS)}

\subsubsection{Procedure}

The real group received biphasic rSMS using a Magstim Super Rapid (Magstim, Whitland, UK) stimulator connected to a $120-\mathrm{mm}$ outer diameter figure-of- 8 air film cooling coil positioned in the mid- line over the sacral vertebrae (approximately $5 \mathrm{~cm}$ above the natal cleft, which approximates to the level of S2) with the handle pointing upwards. $15 \mathrm{~Hz}$ stimulation was delivered at an intensity that produced a sense of contraction of the prenium or inner aspect of the thigh (usually around 50\% of maximum stimulator output). Stimulation was applied in bursts of $10 \mathrm{sec}-$ onds on and 30 seconds off with a total of 1500 pulses. Treatment was repeated for 10 sessions, 5 sessions per week with 2 days off. This regimen was a practical schedule for patients.

The control group received sham rSMS using the same coil, the same session frequency, in the same setting, but the coil was tilted by 90 degree so, that little magnetic field could reach the underlying neural tissue (Khedr et al., 2014).

\subsection{Outcomes}

Primary outcome: The primary outcome was the improvement of number of bedwetting/week (one month pre stimulation, first and second week of stimulations and then one month later after the end of stimulation).

Secondary outcomes: Quality of life and VAS were assessed after the end of the treatment sessions and one month later.

We assessed resting and active motor thresholds pre first session and 1/2 hour after the last treatment session. Evaluation of different scales and motor thresholds were performed blindly by investigators who were unaware of the type of rSMS group.

\subsection{Ethical approval}

The study was approved by the Institutional Ethical Committee of Assiut University Hospital. Prior to the investigation, patients gave their informed consent according to the declaration of Helsinki.

\subsection{Statistical analysis}

The SPSS version 16 package was used in this study. Mann-Whitney non parametric $U$ tests were used to compare demographic and clinical data between the experimental and the control group. $P$ values of $<0.05$ were considered significant. Two factor analysis of variance (ANOVA) for repeated measurements analysis of variance with "treatment" (ie, real or sham rSMS) and "time" (before, 1st and 2nd week 
of stimulations and, 1-month later) as the main factors was used to compare the differential effects of the rSMS conditions on changes on frequency of wet night/week and on VAS. Post hoc unpaired $t$ tests were carried out for comparisons at each time point of assessment. For SF-36v2 Health Survey and for MT analysis; 2-way ANOVA repeated measures analysis time (pre-post one month and pre-post sessions respectively) $\times$ group (real vs sham) were used. When necessary, a Greenhouse-Geisser correction was applied to correct for non-sphericity. Paired $t$ tests were used to compare the RMT and AMT pre-post session for each group separately.

\section{Results}

There were no differences at baseline between the groups as regard to demographic, clinical data, frequency of wet nights/week, resting and active motor threshold and the two rating scales (VAS and SF-36v2 Health Survey) (Table 1). There was no side effects recorded from rSMS in the present study.
Figure 2 illustrates the effect of treatment on frequency of wet nights/week and on the VAS. A repeated measures two-way ANOVA with TIME (one month pre-stimulation, during the 1st, 2nd weeks of stimulation and one month later) and GROUP (real or sham) as main factors showed a significant TIME $\times$ GROUP interaction for the frequency of wet nights/week $(\mathrm{F}=7.79, \mathrm{df}=2.58$, and $P=0.0001)$ and for VAS $(\mathrm{F}=10.4, \mathrm{df}=1.7$ and $P=0.0001)$. This indicates that real stimulation had a different effect to sham on the frequency of wet nights/week and on the VAS (Table 2). We then examined the effect of TIME on the data from each group separately. There was a significant effect of time in both groups on frequency of wet nights/week $(P=0.0001)$. Thus both real and sham treatments tended to reduce symptoms. However, the effects on both measures were greater with real than sham stimulation. The results of individual $t$-test comparisons between groups at each time point in comparison to the baseline assessment are shown on the Fig. 2. Table 3 compares the percentage improvement in frequency of wet nights/week at the end of session and one month later in the two groups.

Table 1

Demographic and clinical data, resting and active motor threshold and generic health survey (SF-36v2 Health Survey) of real and sham groups

\begin{tabular}{|c|c|c|c|}
\hline Variables & $\begin{array}{c}\text { Real group } \\
\quad N=22\end{array}$ & $\begin{array}{c}\text { Sham group } \\
\qquad N=19\end{array}$ & $P$ value \\
\hline Age $($ mean $\pm S D)$ years & $14.5 \pm 3.4$ & $12.9 \pm 3.2$ & 0.129 \\
\hline Sex male/female & $7 / 15$ & $5 / 14$ & 0.69 \\
\hline Order of birth (mean $\pm \mathrm{SD})$ & $2.1 \pm 1.2$ & $1.7 \pm 0.7$ & 0.253 \\
\hline \multicolumn{4}{|l|}{ Education (number $(\%)$} \\
\hline Primary school & $7(31.8 \%)$ & $7(36.8 \%)$ & \multirow[t]{3}{*}{0.182} \\
\hline Prep school & $10(45.5 \%)$ & $9(47.4 \%)$ & \\
\hline Secondary school & $5(22.7 \%)$ & $3(15.8 \%)$ & \\
\hline Positive Family history (number (\%) & $10(45.5 \%)$ & $6(31.58 \%)$ & 0.364 \\
\hline Frequency of enuresis/week (mean $\pm \mathrm{SD}$ ) & $5.7 \pm 2.2$ & $6.5 \pm 1.3$ & 0.162 \\
\hline Visual analogue scale (mean $\pm \mathrm{SD})$ & $6.1 \pm 1.1$ & $5.9 \pm 0.9$ & 0.652 \\
\hline $\begin{array}{l}\text { Resting motor threshold of gastrocnemius } \\
\text { muscle (mean } \pm \text { SD) }\end{array}$ & $69.7 \pm 2.7$ & $70.5 \pm 2.6$ & 0.592 \\
\hline $\begin{array}{l}\text { Active motor threshold of gastrocnemius } \\
\text { muscle (mean } \pm \text { SD) }\end{array}$ & $57.7 \pm 3.1$ & $57.7 \pm 4.3$ & 0.99 \\
\hline \multicolumn{4}{|l|}{ SF-36v2 Health Survey (Physical Health) (mean \pm SD) } \\
\hline General Health $(\mathrm{GH})$ & $60.9 \pm 16.4$ & $59.7 \pm 20.4$ & 0.842 \\
\hline Physical Functioning (PF) & $77.4 \pm 18.4$ & $63.5 \pm 22.5$ & 0.148 \\
\hline Role-Physical (RP) & $86.6 \pm 25$ & $84.2 \pm 32.5$ & 0.797 \\
\hline Bodily Pain (BP) & $81.4 \pm 11.4$ & $71.5 \pm 23.6$ & 0.109 \\
\hline Component of Physical health Summation (CPHS) & $80.1 \pm 12.9$ & $70.7 \pm 15.6$ & 0.120 \\
\hline \multicolumn{4}{|l|}{ SF-36v2 Health Survey (Mental Health) (mean \pm SD) } \\
\hline Role-Emotional (RE) & $83.3 \pm 29$ & $59.6 \pm 46.6$ & 0.065 \\
\hline Social Functioning (SF) & $47.7 \pm 23.3$ & $47 \pm 20.9$ & 0.921 \\
\hline Vitality (VT) & $62 \pm 12.4$ & $56.1 \pm 11$ & 0.109 \\
\hline Mental Health (MH) & $51.1 \pm 16.4$ & $49.3 \pm 17.1$ & 0.724 \\
\hline Component Mental Health Summation (CMHS) & $60.7 \pm 12.6$ & $53.2 \pm 17.2$ & 0.125 \\
\hline Health transition $(\mathrm{HT})$ & $79.8 \pm 25.8$ & $81.6 \pm 14$ & 0.781 \\
\hline
\end{tabular}



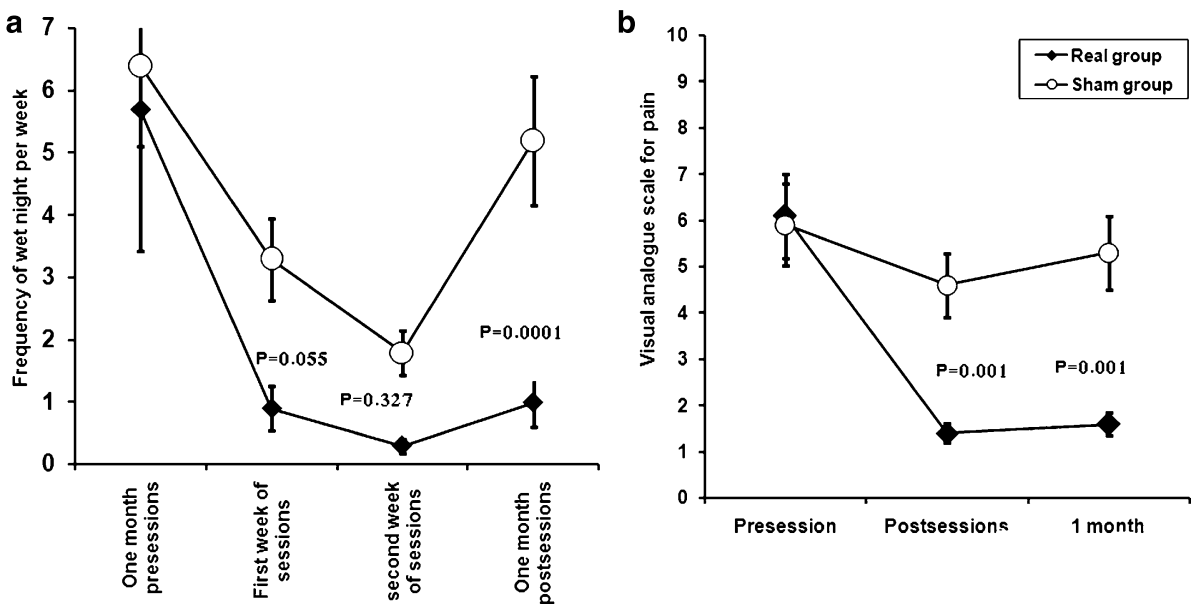

Fig. 2. Shows changes in the frequency of wet night/week (a), and the changes of the visual analogue scale (b) in patients with monosymptomatic nocturnal enuresis at different points of assessment. The frequency of wet night/week was assessed one month prior to sacral stimulation (first point), first week of stimulation (second point), second week of stimulation (third point and one month after the end of stimulation (fourth point). On VAS scale 3 points of assessment one month before, after the end of stimulation and one month after. Data expressed as mean \pm Standard Errors (SE). The significances between groups appeared at different points of assessment in comparison to base line assessment. These were seen mainly in the frequency of wet night/week one month after the end of stimulation and for VAS appeared after the end of stimulation and one month later.

Table 2

Frequency of wet night/week and Visual analogue scale changes on pre-session and follow assessment among studied groups

\begin{tabular}{|c|c|c|c|c|c|}
\hline Group & Pre-session & $\begin{array}{l}\text { 1st week of } \\
\text { stimulation }\end{array}$ & $\begin{array}{l}\text { 2nd week of } \\
\text { stimulation }\end{array}$ & 1 month & $\begin{array}{l}P \text { value } \\
\text { time } \times \text { group }\end{array}$ \\
\hline \multicolumn{6}{|c|}{ Frequency of wet night/week } \\
\hline $\begin{array}{l}\text { Real group } N=22 \\
\text { Sham group } N=19\end{array}$ & $\begin{array}{l}5.7 \pm 2.2 \\
6.5 \pm 1.3\end{array}$ & $\begin{array}{l}0.9 \pm 1.6 \\
3.3 \pm 2.1\end{array}$ & $\begin{array}{l}0.3 \pm 1.1 \\
1.8 \pm 2.5\end{array}$ & $\begin{array}{c}1 \pm 1.9 \\
5.2 \pm 3.2\end{array}$ & $\begin{array}{c}\mathrm{df}=2.6, \mathrm{~F}=7.79, \\
P=0.0001\end{array}$ \\
\hline \multicolumn{6}{|c|}{ Visual analogue scale (VAS) } \\
\hline & Pre-session & Post-session & & 1 month & $\begin{array}{l}P \text { value } \\
\text { time } \times \text { group }\end{array}$ \\
\hline $\begin{array}{l}\text { Real group } N=22 \\
\text { Sham group } N=19\end{array}$ & $\begin{array}{l}6.1 \pm 1.1 \\
5.9 \pm 0.9\end{array}$ & $\begin{array}{l}1.4 \pm 2.2 \\
4.6 \pm 2.7\end{array}$ & & $\begin{array}{l}1.6 \pm 2.8 \\
5.3 \pm 3.3\end{array}$ & $\begin{array}{c}\mathrm{dF}=1.7, \mathrm{~F}=10.4, \\
P=0.0001\end{array}$ \\
\hline
\end{tabular}

Table 3

Percentage changes of improvement in frequency of wet night/week

\begin{tabular}{lrrr}
\hline $\begin{array}{l}\text { Time of } \\
\text { assessment }\end{array}$ & $\begin{array}{r}\text { Real group } \\
N=22(\%)\end{array}$ & $\begin{array}{c}\text { Sham group } \\
N=19(\%)\end{array}$ & $P$ value \\
\hline Post sessions & & & \\
Improvement $<50 \%$ & $4(19.2 \%)$ & $11(57.9 \%)$ & 0.008 \\
$\quad$ Improvement $\geq 50 \%$ & $18(81.8 \%)$ & $8(42.1 \%)$ & \\
One month post sessions & & & \\
Improvement $<50 \%$ & $4(19.2 \%)$ & $13(68.4 \%)$ & 0.001 \\
Improvement $\geq 50 \%$ & $18(81.8 \%)$ & $6(31.6 \%)$ & \\
\hline
\end{tabular}

Secondary outcome measures: Table 4 shows the scores on the SF-36v2 Health Survey at baseline and at one month after stimulation. There were significantly greater improvements in the score of the Mental health domain including Social Functioning (SF), Vitality (VT), Mental Health (MH) and component Mental Health Summation (CMHS) in the real group compared with the sham group (Fig. 3). However there was no significant difference between groups in different components of Physical health.

There was a significant time $\times$ group interaction for RMT $(\mathrm{F}=4.6, \mathrm{df}=1$, and $P=0.03)$ which was due to the fact that there was significant reduction in RMT after real stimulation (one way ANOVA effect of time: $\mathrm{T}=4.03, \mathrm{df}=17$, and $P=0.001$ ) but not the sham group $((\mathrm{T}=0.04$ and $\mathrm{df}=16$, and $P=0.96)$. There was neither a significant time $\times$ group interaction nor a main effect of time for measures of AMT, indicating that these did not change in either group (Fig. 4). 
Table 4

Quality for life (SF-36v2 Health Survey) on pre and post sessions (one month pre and post stimulation) among studied groups

\begin{tabular}{|c|c|c|c|}
\hline Group & Pre-session & 1 month post stimulations & $P$ value time $\times$ group \\
\hline \multicolumn{4}{|l|}{ General Health $(\mathrm{GH})$} \\
\hline Real group $n=22$ & $60.9 \pm 16.4$ & $67.4 \pm 20.2$ & \multirow[t]{2}{*}{$\mathrm{Df}=1, \mathrm{~F}=1.64, P=0.208$} \\
\hline Sham group $n=19$ & $59.7 \pm 20.4$ & $59.3 \pm 23.6$ & \\
\hline \multicolumn{4}{|c|}{ Physical functioning (PF) } \\
\hline Real group $n=22$ & $77.4 \pm 18.4$ & $91.4 \pm 15.3$ & \multirow{2}{*}{$\mathrm{Df}=1, \mathrm{~F}=0.5, P=0.479$} \\
\hline Sham group $n=19$ & $63.5 \pm 22.5$ & $82.9 \pm 20.5$ & \\
\hline \multicolumn{4}{|l|}{ Role-Physical (RP) } \\
\hline Real group $n=22$ & $86.6 \pm 25$ & $88.2 \pm 20.3$ & \multirow[t]{2}{*}{$\mathrm{DF}=1, \mathrm{~F}=0.307, P=0.583$} \\
\hline Sham group $n=19$ & $84.2 \pm 32.5$ & $90.8 \pm 23.9$ & \\
\hline \multicolumn{4}{|l|}{ Bodily Pain (BP) } \\
\hline Real group $n=22$ & $81.4 \pm 25.1$ & $87 \pm 15.4$ & \multirow{2}{*}{$\mathrm{DF}=1, \mathrm{~F}=1.69, P=0.201$} \\
\hline Sham groupn $=19$ & $72.5 \pm 28.4$ & $69.2 \pm 23.3$ & \\
\hline \multicolumn{4}{|c|}{$\begin{array}{l}\text { Component of Physical } \\
\text { health Summation (CPHS) }\end{array}$} \\
\hline Real group $n=22$ & $80.1 \pm 12.9$ & $81.4 \pm 11.4$ & \multirow[t]{2}{*}{$\mathrm{DF}=1, \mathrm{~F}=0.012, P=0.914$} \\
\hline Sham group $n=19$ & $70.7 \pm 15.6$ & $71.5 \pm 23.6$ & \\
\hline \multicolumn{4}{|l|}{ Role-Emotional (RE) } \\
\hline Real group $n=22$ & $83.3 \pm 29$ & $90.6 \pm 20.4$ & \multirow[t]{2}{*}{$\mathrm{DF}=1, \mathrm{~F}=0.300, P=0.587$} \\
\hline Sham group $n=19$ & $59.6 \pm 46.6$ & $61.2 \pm 35.6$ & \\
\hline \multicolumn{4}{|l|}{ Social functioning (SF) } \\
\hline Real group $n=22$ & $47.7 \pm 23.3$ & $76.8 \pm 21$ & \multirow[t]{2}{*}{$\mathrm{DF}=1, \mathrm{~F}=11.667, P=0.001$} \\
\hline Sham group $n=19$ & $47 \pm 20.9$ & $48 \pm 25.8$ & \\
\hline \multicolumn{4}{|l|}{ Vitality (VT) } \\
\hline Real group $n=22$ & $62 \pm 12.4$ & $76.7 \pm 15.7$ & \multirow[t]{2}{*}{$\mathrm{Df}=1, \mathrm{~F}=11.134, P=0.002$} \\
\hline Sham group $n=19$ & $56.1 \pm 11$ & $56.4 \pm 14.7$ & \\
\hline \multicolumn{4}{|l|}{ Mental health (MH) } \\
\hline Real group $n=22$ & $51.1 \pm 16.4$ & $69.1 \pm 23.4$ & \multirow[t]{2}{*}{$\mathrm{df}=1, \mathrm{~F}=7.893, P=0.008$} \\
\hline Sham group $n=19$ & $49.3 \pm 17.1$ & $50.2 \pm 18$ & \\
\hline \multicolumn{4}{|c|}{$\begin{array}{l}\text { Component mental } \\
\text { health summation CMHS }\end{array}$} \\
\hline Real group $n=22$ & $60.7 \pm 12.6$ & $78.5 \pm 15.5$ & \multirow{2}{*}{$\mathrm{df}=1, \mathrm{~F}=10.725, P=0.002$} \\
\hline Sham group $n=19$ & $53.2 \pm 17.2$ & $54.3 \pm 16$ & \\
\hline \multicolumn{4}{|l|}{ Health transition (HT) } \\
\hline Real group $n=22$ & $78.8 \pm 26$ & $80 \pm 25.1$ & \multirow[t]{2}{*}{$\mathrm{df}=1, \mathrm{~F}=2.497, P=0.123$} \\
\hline Sham group $n=19$ & $81.9 \pm 14.4$ & $70.8 \pm 19.6$ & \\
\hline
\end{tabular}

\section{Discussion}

The present study examined the effect of 10 days of rSMS in 41 patients with MNE. All of them continued oral $25 \mathrm{mg}$ imipramine (anticholinergic drug) throughout treatment and follow up. Both groups were matched at baseline for clinical characteristics, VAS, and quality of life. Both groups showed a significant improvement in symptoms immediately after treatment, but the effect was more pronounced in the real than the sham group. The average number of weekly nocturnal episodes fell from 5.7 to $0.3 /$ week after end of the treatment sessions for real group versus 6.5 to 1.8 /week after sham stimulation. The improvement in the real group continued one month later (1/week) whereas the sham group returned to baseline behaviour (5.2/week). The initial improvement in the sham group highlights the necessity of a control group in rSMS studies. The results were reflected in effects on measures of quality of life using the VAS and SF-36v2 Health Survey (especially mental health components). Improvement in the latter was observed only in real group at one month follow up.

The present study combined rSMS with oral imipramine (Tricyclic anti-depressants). With this combination we found that $81 \%$ of patients in the real group had a good improvement $(>50 \%)$ while only $19 \%$ had a poor response. Since we did not study a group of patients who were untreated with tricyclic anti-depressants, we cannot say whether rSMS alone 

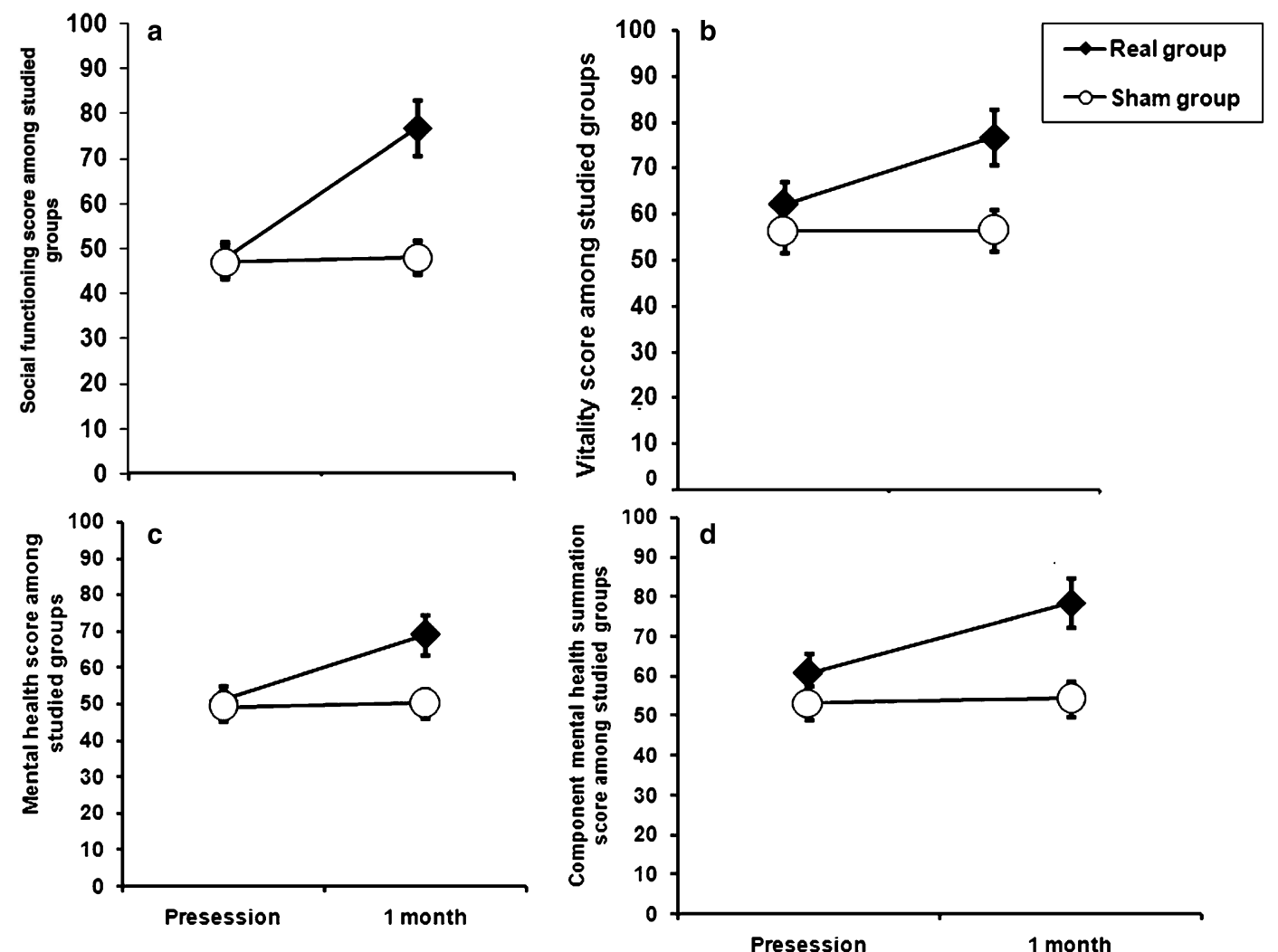

Fig. 3. Shows changes in the score of Quality of lie (SF-36v2 Health survey) in patients with monosymptomatic nocturnal enuresis in the two studied groups before and one month after the end of stimulation. There were significant improvement in the score of Mental health domains including Social Functioning (SF), Vitality (VT), Mental Health (MH) and Component Mental Health Summation (CMHS) in real group versus sham group. However there was no significant difference between groups in different component of Physical health. Data expressed as mean \pm Standard Errors (SE).

would improve symptoms. However, the response rate compares favorably with that of treatment with anticholinergics, in which response rates of up to $50 \%$ have been reported (Raes et al., 2004).

The mechanism of action of rSMS is unclear. Tricyclic anti-depressants such as imipramine act centrally by inhibiting neuronal re-uptake of noradrenaline and serotonin, thereby prolonging their effect. They have also been shown to have anti-cholinergic properties, though it is unlikely they exert their effect in this way as they are often successful in patients who have previously failed anticholinergic treatment (Glazener \& Evans, 2002). In the present study rSMS could have increased arousal or enhanced inhibition of neuronal re-uptake of noradrenaline and serotonin. We have previously reported that patients with nocturnal enuresis have pathologically increased excitability and reduced inhibitory processing in the motor cortex (Khedr et al.,
2015), and it is possible that rSMS could affect these measures as well.

Although we cannot be certain, it seems likely that rSMS produced some of its effect in the present patients by a direct effect on bladder control. Sheriff et al. (1996) first showed that rSMS produced an acute suppression of detrusor hyper-reflexia in seven spinal injured patients with neurogenic detrusor overactivity. Similarly, McFarlane et al. (1997) demonstrated an 80-98\% decrease in provoked detrusor contractions in patients with idiopathic detrusor overactivity following sacral magnetic stimulation. The value of rSMS in the inhibition of detrusor contractions was reported also by Yamanishi et al. (2000) who's compared the results of FMS (pulsegen device) with the electric stimulation, and found that the bladder capacity was significantly greater in the group of patients who underwent magnetic stimulation. Detrusor over activity was abolished 

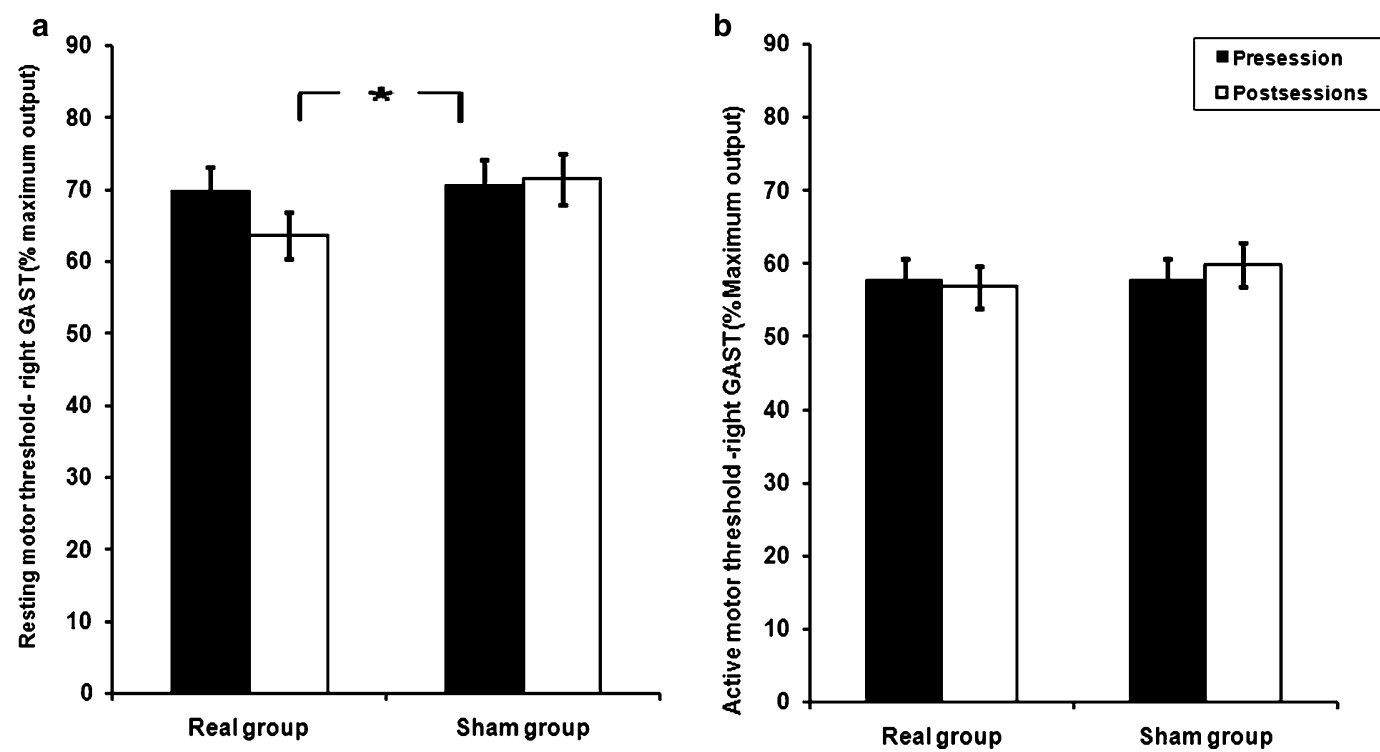

Fig. 4. Shows changes in the resting and active motor threshold pre-post-sessions in patients with monosymptomatic nocturnal enuresis in the two studied groups. There was a significant decrease in resting motor threshold after session in real group in comparison to sham group, while no such change was recorded in active motor threshold. Data expressed as mean \pm Standard Errors (SE).

in 3 patients (20\%) from the FMS group but no patients in the functional electric stimulation group (Yamanishi et al., 2000).

rSMS may also stimulate directly the pudendal nerve efferent fibers to both external and internal urethral sphincters and activate contractile mechanisms. Indeed, stimulation of the sacral nerve roots at 15 to $20 \mathrm{~Hz}$ has been shown to be the optimal frequency to provide contraction of the anal sphincter (Trsinar et al., 1984). Stimulation at the intensity levels used in this study will also activate directly the peripheral afferent fibers and evoke sensory input to spinal cord together with additional input from the induced muscle contraction. Combined, all these inputs could increase excitability of sensorimotor connections in the cord and cortex. This may contribute to the changes observed in resting motor threshold after real SMS in the present study. Although these were measured in leg muscles, it is possible that this input could also increase the excitability of cortico-urtheral pathways at rest and improve descending control of the bladder.

It is likely that changes are mediated by supraspinal as well as spinal pathways, as evidenced by recent work showing EEG activity in the post-central gyrus during S3 stimulation (Braun et al., 2002).
An alternative mode of action of electrostimulation is that sub threshold excitation of the pudendal nerve serves to feed forward into the micturition reflex. If the detrusor is overly active, current-induced pudendal afferent activity will stimulate spinal and paraspinal inhibition or act as an alternative inhibitory system. This stabilization of the micturition reflex may also be a result of a decrease in sphincter overactivity (Tanagho, 1992).

\section{Limitation of the study}

The small number of studied sample and the short duration of the follow up, were major limitations of this study.

\section{Conclusion and recommendation}

Our data demonstrate that in patients with MNE treated by rSMS, has potential as an adjuvant treatment for PNE.

Further trials are needed to determine the optimum stimulation protocols and to compare magnetic stimulation with other forms of conservative treatment. 


\section{Funding}

The author(s) received no financial support for the research, authorship, and/or publication of this article.

\section{Conflict of interest}

We declare no conflict of interest.

\section{References}

Almeida, F.G., Bruschini, H., \& Srougi, M. (2004). Urodynamic and clinical evaluation of 91 female patients with urinary incontinence treated with perineal magnetic stimulation: 1-year follow-up. J Urol, 171(4), 1571-1574.

Amerian Psychiatric Association (1994). Diagnostic and Statistical Manual of Mental Disorders. 4th Edition. Washington, DC: American Psychiatric Association.

Braun, P.M., Baezner, H., Seif, C., Boehler, G., Bross, S., Eschenfelder, C.C., Alken, P., Hennerici, M., \& Juenemann, P. (2002). Alterations of cortical electrical activity in patients with sacral neuromodulator. Eur Urol, 41, 562-566.

But, I., \& Marčun Varda, N. (2006). Functional magnetic stimulation: A new method for the treatment of girls with primary nocturnal enuresis? Journal of Pediatric Urology, 2(5), 415e-418e.

Butler, R.J., \& Holland, P. (2000). The three systems: A conceptual way of understanding nocturnal enuresis. Scand J Urol Nephrol, 34(4), 270-277.

Butler, R.J., \& Heron, J. (2008). The prevalence of infrequent bedwetting and nocturnal enuresis in childhood. A large British cohort. Scand J Urol Nephrol, 42(3), 257-264.

Caldwell, K.P. (1963). The electrical control of sphincter incompetence. Lancet, 2(7300), 174-175.

Deshpande, A.V., \& Caldwell, P.H. (2012). Medical management of nocturnal enuresis. Paediatr Drugs, 14(2), 71-77. doi: 10.2165/11594870-000000000-00000

Fujishiro, T., Takahashi, S., Enomoto, H., Ugawa, Y., Ueno, S., \& Kitamura, T. (2002). Magnetic stimulation of the sacral roots for the treatment of urinary frequency and urge incontinence: An investigational study and placebo controlled trial. J Urol, 168(3), 1036-1039.

Glazener, C.M.A., \& Evans, J.H.C. (2002). Desmopressin for nocturnal enuresis in children. Cochrane Database of System Rev, (3), CD002112.

Glen, E.S., Samuels, B.M., MacKenzie, I.M., \& Rowan, D. (1976). Maximal perineal stimulation for urinary incontinence. Urol Int, 31(1-2), 134-136.

Harris, M.L., Singh, S., Rothwell, J., Thompson, D.G., \& Hamdy, S. (2008). Rapid rate magnetic stimulation of human sacral nerve roots alters excitability within the cortico-anal pathway. Neurogastroenterol Motil, 20, 1132-1139.
Karim, A.A., Kammer, T., Lotze, M., Hinterberger, T., Godde, B., Cohen, L., \& Birbaumer, N. (2003). Effects of repetitive transcranial magnetic stimulation (rTMS) on slow cortical potentials (SCP). Suppl Clin Neurophysiol, 56, 331-337.

Khedr, E.M., Alkady, E.A., El-Hammady, D.H., Khalifa, F.A., \& Bin-Humam, S. (2011). Repetitive lumbosacral nerve magnetic stimulation improves bladder dysfunction due to lumbosacral nerve injury: A pilot randomized controlled study. Neurorehabil Neural Repair, 25(6), 570-576.

Khedr, E.M., Abo El-Fetoh, N., Ali, A.M., El-Hammady, D.H., Khalifa, H., Atta, H., \& Karim, A.A. (2014). Dual-hemisphere repetitive transcranial magnetic stimulation for rehabilitation of poststroke aphasia: A randomized, double-blind clinical trial. Neurorehabil Neural Repair, 28(8), 740-750.

Khedr, E.M., Abo-Elfetoh, N., Elbeh, K.A., Baky, A.A., Gamal, R.M., El-Hammady, D., \& Korashy, F. (2015). Transcranial magnetic stimulation identifies cortical excitability changes in monosymptomatic nocturnal enuresis. Neurophysiol Clin, 2015; Apr 22. pii: S0987-7053(15)00018-0. doi: 10.1016/ j.neucli.2015.02.001

Lisanby, S.H., Gutman, D., Luber, B., Schroeder, C., \& Sackeim, H.A. (2001). Sham TMS: Intracerebral measurement of the induced electrical field and the induction of motor-evoked potentials. Biological Psychiatry, 49(5), 460-463.

Lordêlo, P., Benevides, I., Kerner, E.G., Teles, A., Lordêlo, M., \& Ubirajara Barroso, U., Jr. (2010). Treatment of non-monosymptomatic nocturnal enuresis by transcutaneous parasacral electrical nerve stimulation. J Pediatr Urol, 6(5), 486-489.

Lottmann, H.B., \& Alova, I. (2007). Primary monosymptomatic nocturnal enuresis in children and adolescents. Int J Clin Pract Suppl (155), 8-16.

McFarlane, J.P., Foley, S.J., De Winter, P., Shah, P.J., \& Craggs, M.D. (1997). Acute suppression of idiopathic detrusor instability with magnetic stimulation of the sacral nerve roots. $\mathrm{Br} \mathrm{J}$ Urol, 80(50), 734-741.

Nevéus, T. (2003). The role of sleep and arousal in nocturnal enuresis. Acta Paediatr, 92(10), 1118-1123.

Plevnik, S., Janei, J., Vrta Enik, P., Trsinar, B. \& VoduSek, D.B. (1986). Short-term electrical stirnulation: Home treatment for urinary incontinence. World J Urol, (4), 24-26.

Quek, P. (2005). A critical review on magnetic stimulation: What is its role in the management of pelvic floor disorders? Curr Opin Urol, 15(4), 231-235.

Raes, A., Hoebeke, P., Segaert, I., Van Laecke, E., Dehoorne, J., \& Vande Walle, J. (2004). Retrospective analysis of efficacy and tolerability of tolterodine in children with overactive bladder. Eur Urol, 45(2), 240-244.

Sheriff, M.K.M., Shah, P.J.R., Fowler, C., Mundy, A.R., \& Craggs, M.D. (1996). Neuromodulation of detrusor hyperreflexia by functional magnetic stimulation of the sacral roots. Br J Urol, $78(1), 39-46$.

Stewart, A.L., \& Ware, J.E. (1992). Measuring Functioning and Well-Being: The Medical Outcomes Study Approach, Duke University Press, Durham, NC.

Suhel, P. (1976). Adjustable no implantable electrical stimulators for correction of urinary incontinence. Urol Int, 31(1-2), 115-123. 
Tanagho, E.A. (1992). Neuromodulation in the management of voiding dysfunction in children. J Urol, 148(2 Pt 2), 655-657.

Trsinar, B., \& Kraij, M. (1996). Maximal electrical stimulation in children with unstable bladder and nocturnal enuresis and/or daytime incontinence: A controlled study. Neurourol Urodyn, 15(2), 133-142.

Trsinar, B., Plevnik, S., VrtaEnik, P. \& Drobni, E.J. (1984). Maximal electrical stimulation for enuresis. Proc Int Cont SOC, 14th Meet, Innsbruck, pp. 459-462.

van Balken, M.R., Vergunst, H., \& Bemelmans, B.L. (2004). The use of electrical devices for the treatment of bladder dysfunction: A review of methods. $J$ Urol, 172(3), 846-8451.
Yamanishi, T., Sakakibara, R., Uchiyama, T., Suda, S., Hattori, T., Ito, H., \& Yasuda, K. (2000). Comparative study of the effects of magnetic versus electrical stimulation on inhibition of detrusor overactivity. Urology, 56(5), 777-781.

Yamanishi, T., Yasuda, K., Suda, S., \& Ishikawa, N. (1999). Effect of functional continuous magnetic stimulation on urethral closure in healthy volunteers. Urology, 54(4), 652-655.

Yeung, C.K., Chiu, H.N., \& Sit, F.K.Y. (1999). Bladder dysfunction in children with refractory monosymptomatic primary nocturnal enuresis. J Urol, 162(3 Pt 2), 1049-1054. 